\title{
Plan spawania kolejowej Ramy Kompresora w oparciu o wymagania EN 15085
}

\author{
Plan of welding the railway compressor frame based \\ on the requirements of the EN 15085 standard
}

\section{Streszczenie}

Przedstawiono plan spawania Ramy Kolejowej Kompresora. Omówiono w nim zagadnienia dotyczące materiałów dodatkowych, przygotowanie elementów do spawania, sczepiania oraz przebiegu procesu spawania. Zaprezentowano przykłady Kart Technologicznych pokazujące poszczególne etapy sczepiania i spawania dla konkretnej kolejowej Ramy Kompresora.

Słowa kluczowe: spawanie, plan spawania, pojazdy szynowe, kontrola spawania

\begin{abstract}
A plan of welding the railway compressor frame is presented in the above article. Issues referring to additional materials, preparation of components for welding, tacking and welding processes are discussed. Examples of operation sheets which show various stages of tacking and welding for the particular railway compressor frames are provided.
\end{abstract}

Keywords: welding, welding plan, rail vehicles, control of welding

\section{Wstęp}

Przedstawiona instrukcja dotyczy warunków techniczno - technologicznych wykonania prac spawalniczych przy spawaniu kolejowej Ramy Kompresora przedstawionej na rysunek 1 .
Rys. 1. Rama Kompresora

Fig. 1. Compressor's frame

Przedmiotem niniejszej instrukcji jest opracowanie i usystematyzowanie poszczególnych kroków sczepiania i spawania, elementów składowych kolejowej Ramy Kompresora. Zawiera ona również instrukcje technologiczne WPS - opisujące szczegółowo warunki prowadzenia prac spawalniczych przy produkcji konkretnej kolejowej Ram Kompresora [1 $\div 18]$.
Instrukcja odnosi się do wszystkich produkowanych kolejowych Ram Kompresora wykonywanych zgodnie z dokumentacją nr. ABC.

\section{Wymagania techniczne szczegółowe}

\section{Materiały podstawowe}

Materiały używane do spawania Ram Kompresora musza odpowiadać następującym wymaganiom:

- gatunki używanych materiałów muszą ściśle odpowiadać gatunkom podanym w dokumentacji konstrukcyjnej,

- wszystkie materiały powinny posiadać atesty hutnicze, potwierdzające gatunek i własności wytrzymałościowe zastosowanych materiałów.

Podstawowe materiały użyte do wykonania kolejowych Ram Kompresora określonego typu to blachy w zakresie grubości od 1 do $5 \mathrm{~mm}$ w gat. S355J2+N oraz profile wg EN10210 / EN10219 w gat. S355J2H.

\section{Metoda spawania}

Do spawania Ram Kompresora stosuje się wyłącznie spawanie w osłonie aktywnych gazów ochronnych metodą MAG (135), zgodnie z procedurami WPS, będącymi integralną częścią niniejszej instrukcji.

\section{Materiały dodatkowe}

Drut elektrodowy musi posiadać świadectwo jakości (atest producenta) z dopuszczeniem DB i TüV.

Dr hab. Inż. Jacek Słania, prof. PCz - Politechnika Częstochowska; inż. Łukasz Sell - AEBI Schmidt Polska Sp. z o.o., Kielce. Autor korespondencyjny/Corresponding author. jacek_slania@poczta.onet.pl 
Dopuszczone druty elektrodowe to:

- G4Si1 - CARBOFIL 1A $\varphi$ 1,0 / $\varphi$ 0,8 firmy OERLIKON wg. PN-EN ISO 14341: G 463 C G4Si1 / G 464 M G4Si1

- 1.4370 - Thermanit $X \varphi 0,8$ firmy Böhler Thyssen wg. PN-EN ISO 14343: G 188 Mn

\section{Dopuszczony gaz osłonowy to:}

Dla poz. A. wg. EN ISO 14341-A; M21

Dla poz. B. wg. EN ISO 14341-A; M12

\section{Rodzaje spoin}

Do łączenia poszczególnych elementów kolejowej Ramy Kompresora zastosowano spoiny pachwinowe $a=2 \div 7[\mathrm{~mm}]$; oraz spoiny specjalne $1 / 2 \mathrm{Y}$ o grubości 3 [mm].

\section{Przygotowanie elementów do spawania}

Poszczególne elementy składowe Ramy Kompresora musza być wykonane zgodnie z dokumentacją. W trakcie kontroli przed montażem należy zwrócić szczególną uwagę na przygotowanie krawędzi do spawania (ukosowanie detali zgodnie z wymaganiami dokumentacji).

\section{Sczepianie elementów}

Dopasowane i oczyszczone elementy kolejowej Ramy Kompresora należy zestawić i przygotować do sczepiania w kolejności opisanej w załączonych poniżej Kartach Technologicznych Sczepiania i Spawania.

Jednostkowa długość spoiny sczepnej powinna wynosić od 20-30 mm.

Przy wykonaniu spoin sczepnych, należy utrzymywać tzw. „oczko"- którym również należy zakończyć spoinę sczepną.

Po sczepianiu, spoiny należy oczyścić i skontrolować wzrokowo - w przypadku zauważenia wadliwie wykonanych spoin sczepnych, należy je usunąć i wykonać ponownie.

\section{Spawanie}

Przed przystąpieniem do spawania należy oczyścić rowek do stanu metalicznego połysku. Warstwę przetopową, należy wykonać wyjątkowo starannie, ponieważ jakość wykonania tej warstwy ma decydujący wpływ na jakość całej spoiny. Miejsce zajarzenia łuku elektrycznego należy rozpocząć na spinie sczepnej. W trakcie rozpoczynania spawania należy zwrócić szczególną uwagę na dokładne przetopienia tzw. „oczka”, które pozostało na uprzednio wykonanej spoinie sczepnej. Identycznie należy postępować w przypadku zakończenia lub rozpoczęcia spawania nowej warstwy.

Zakończenie warstwy przetopowej należy wykonać na uprzednio wykonanej spoinie sczepnej, zwracając szczególną uwagę na wypełnienie rowka spawalniczego. Warstwę przetopową należy dokładnie skontrolować wzrokowo przed rozpoczęciem dalszych prac spawalniczych.

Wykonując kolejne warstwy należy zwracać uwagę na ich grubość oraz prawidłowe łączenie poszczególnych warstw. Nie dopuszcza się rozpoczynania i kończenia poszczególnych warstw w tych samych miejscach. Miejsca te powinny być przesunięte względem siebie o $\min .30 \mathrm{~mm}$.

Spawając konstrukcje przestrzenne tego typu, należy w miarę możliwości, prowadzić proces spawania (za pomocą zastosowania techniki spawania odcinkowego) w taki sposób, by wprowadzone ciepło podczas spawania było równomiernie rozprowadzone po całej konstrukcji. Spoiny pachwinowe zaleca się układać na przemian-legle, a przy dużej ilości spoin w konstrukcji, należy zatrzymać na pewien czas spawanie celem odprowadzenia ciepła. Długość spoin wykonanych jednym ciągiem od momentu zajarzenia łuku spawalniczego powinna się mieścić w zakresie
150-200 mm.

Spawanie należy rozpocząć w miarę możliwości od środka konstrukcji i prowadzić równomiernie na wszystkie strony. Spawanie zakończeń spoin pachwinowych poza narożniki elementu, musi być w miarę możności wykonane bez przerywania (wg. Załączonego poniżej rys. nr. 2 ) przy czy musi być zachowana wartość $\mathrm{L} \geq 2 \mathrm{t}$ ( $\mathrm{t}$ = grubość blachy), ale nie mniej niż $L_{\min }=10 \mathrm{~mm}$.

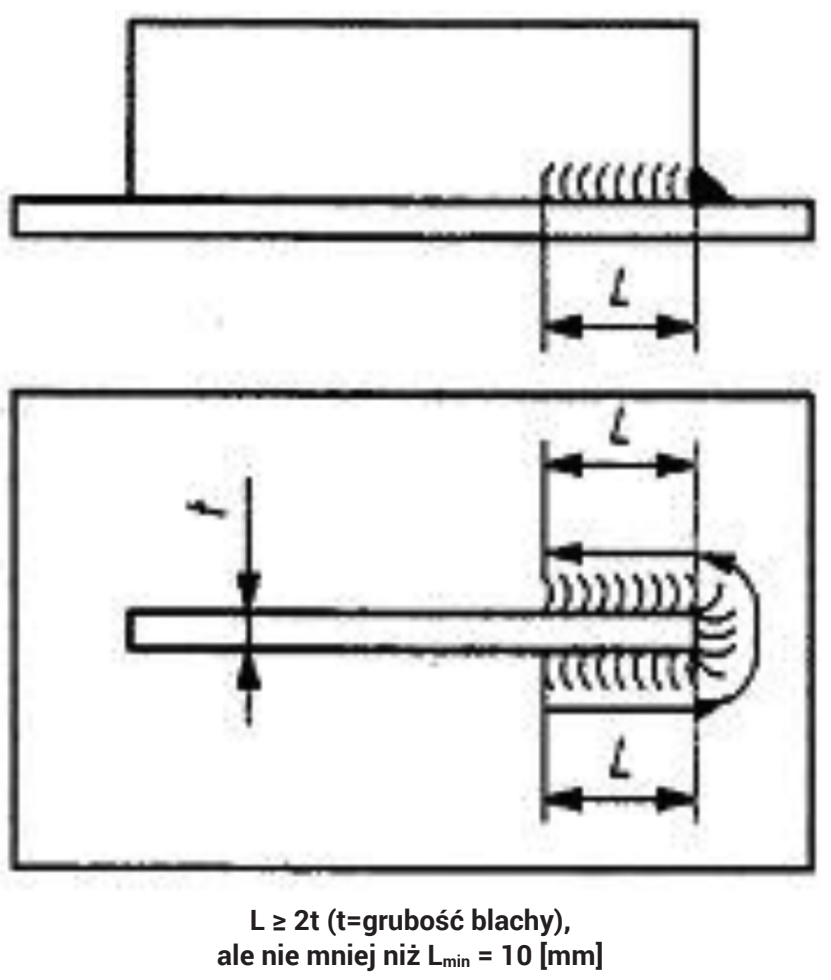

Rys. 2. Spawanie zakończeń spoin pachwinowych

Fig. 2. Welding the ends of the fillet welds

\section{Wykonanie próby roboczej}

W trakcie wykonywania prac spawalniczych przy spawaniu kolejowej Ramy Kompresora należy przeprowadzić próbę roboczą według przyjętej procedury spawalniczej raz na każdą, nowo uwolnioną serię produkcyjną.

\section{Karty Technologiczne}

1. Zawierają wykazy części, których należy użyć przy sczepianiu każdego z etapów składania kolejowej ramy kompresora.

2. Zawierają kolejność składania i sczepiania dla każdego z etapów produkcji kolejowej ramy kompresora.

3. Przywołują odpowiednią procedurę spawalniczą WPS - wg., której mają być wykonane spoiny.

4. Zawierają informacje dodatkowe dotyczące między innymi:

- zachowania powiększonych wymiarów montażowych w celu uzyskania prawidłowego wymiaru po spawaniu.

- zawierają uwagi o zmianie drutu spawalniczego (ze względu na łączone różnoimienne materiały podstawowe) dla prawidłowego wykonania danego etapu spawania

- pokazują kolejność układania ściegów dla danego etapu - jeżeli z punktu technologicznego jest to wymagane.

5. Przedstawiają rysunkowo dany etap sczepiania i spawania. 


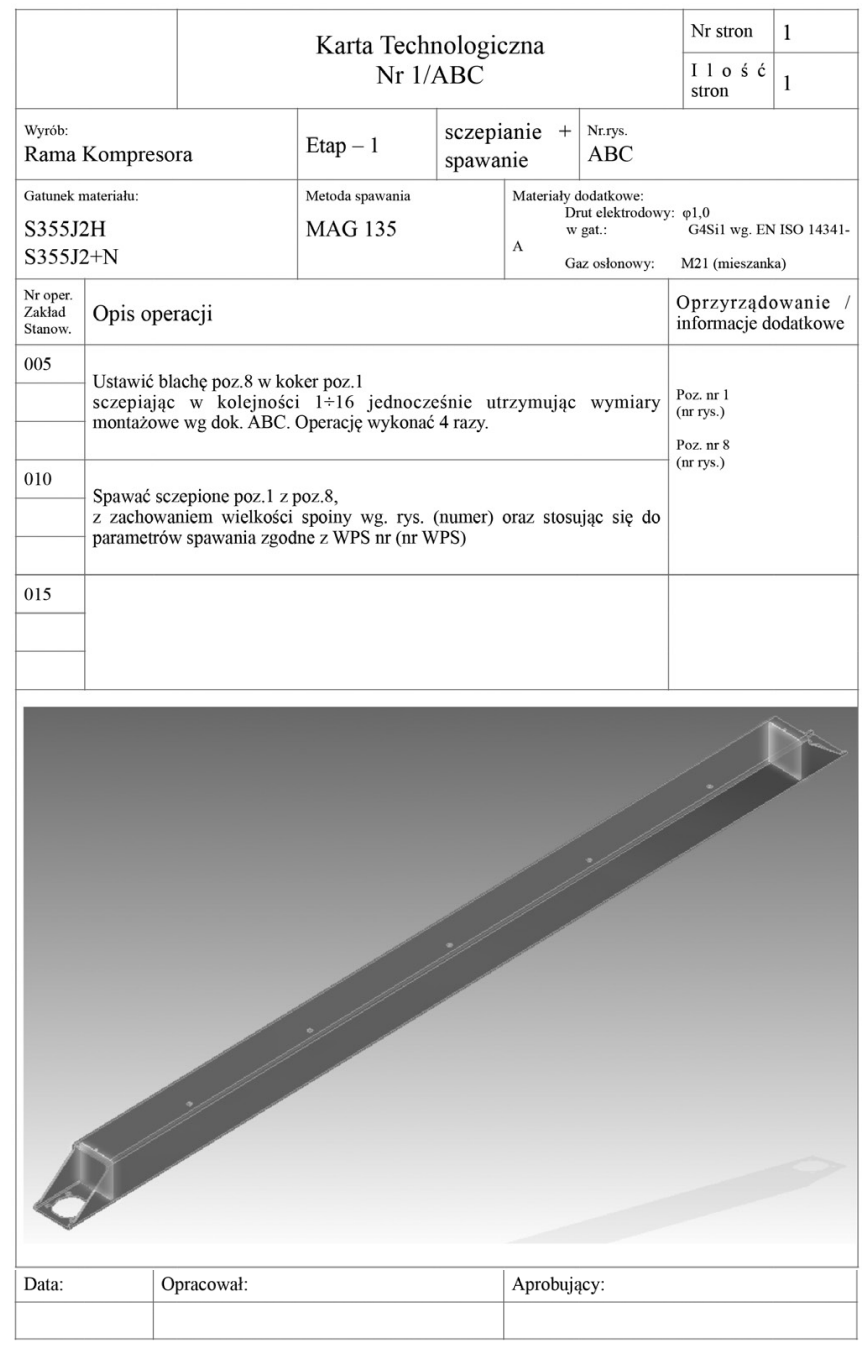

Rys. 3. Karta Technologiczna Nr 1/ABC - Etap - 1

Fig. 3. Operation sheet no. 1 / ABC - Stage - 1

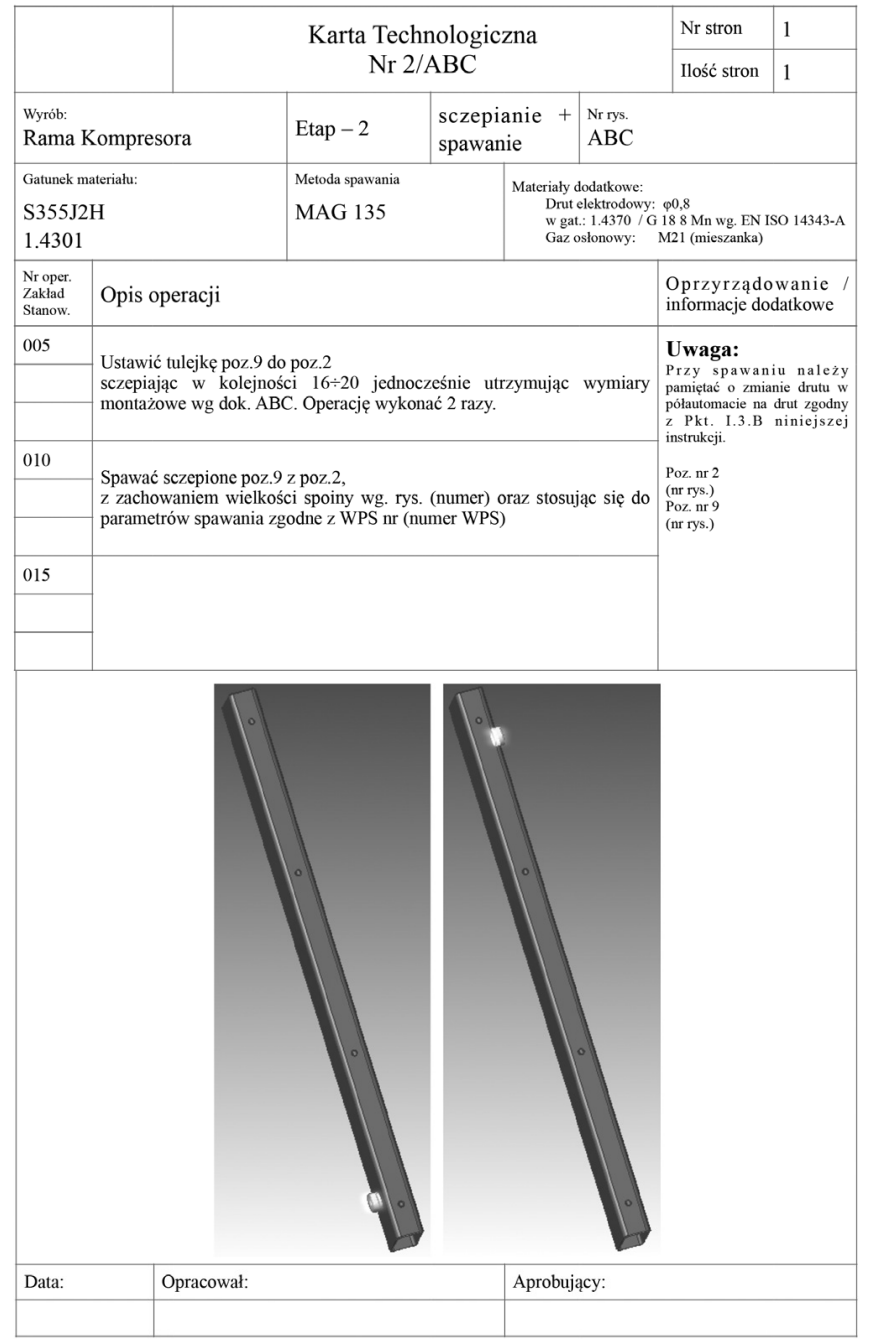

Rys. 4. Karta Technologiczna Nr 2/ABC - Etap - 2

Fig. 4. Operation sheet no. 2 / ABC - Stage - 2

\begin{tabular}{|c|c|c|c|c|c|c|}
\hline & & Karta & nologiczna & & Nr stron & 1 \\
\hline & & & $\mathrm{ABC}$ & & Ilość stron & 1 \\
\hline $\begin{array}{l}\text { Wyrób: } \\
\text { Rama }\end{array}$ & Kompresor & Etap - 3 & $\begin{array}{l}\text { sczepianie } \\
\text { spawanie }\end{array}+$ & $\begin{array}{l}\text { Nr.rys. } \\
\text { ABC }\end{array}$ & & \\
\hline $\begin{array}{l}\text { Gatunek } \\
\mathrm{S} 355 \mathrm{~J} 2 \\
1.4301\end{array}$ & nateriazu: & $\begin{array}{l}\text { Metoda spaw: } \\
\text { MAG } 13\end{array}$ & $\begin{array}{c}\text { Materialy d } \\
\text { Drut el. } \\
\text { w gat.: } \\
\text { Gaz os }\end{array}$ & $\begin{array}{l}\text { lodatkowe: } \\
\text { ettrodowy: } \\
\text { 1.4370/G / } 18 \\
\text { lonowy: M }\end{array}$ & $\begin{array}{l}0,8 \\
88 \text { Mn wg. EN IS } \\
21 \text { (mieszanka) }\end{array}$ & 14343-A \\
\hline $\begin{array}{l}\text { Nr oper. } \\
\text { Zakad } \\
\text { Stanow. }\end{array}$ & Opis ope & & & & $\begin{array}{l}\text { Oprzyrząd } \\
\text { informacje do }\end{array}$ & $\begin{array}{l}\text { owanie } \\
\text { odatkowe }\end{array}$ \\
\hline 005 & $\begin{array}{l}\text { Ustawić tul } \\
\text { sczepiając } \\
\text { montażowe }\end{array}$ & $\begin{array}{l}\text { o blachy poz } \\
\text { ci } 20 \div 28 \text { j } \\
\text { C. Operacje v }\end{array}$ & $\begin{array}{l}\text { ześnie utrzymując } \\
\text { ać } 2 \text { razy. }\end{array}$ & wymiary & $\begin{array}{l}\text { Uwaga: } \\
\text { Przy spa wa } \\
\text { pamietać o zmi } \\
\text { pótautomacie na } \\
\text { z Pkt. I. I.B } \\
\text { instrukcji. }\end{array}$ & $\begin{array}{l}\text { niu należy } \\
\text { ianie drutu w } \\
\text { a drut zgodny } \\
\text { niniejszej }\end{array}$ \\
\hline 010 & $\begin{array}{l}\text { Spawać sc: } \\
\text { z zachowa } \\
\text { do paramet }\end{array}$ & $\begin{array}{l}\text { y z poz. } 15, \\
\text { ci spoiny wg } \\
\text { zgodne z W }\end{array}$ & $\begin{array}{l}\text { (numer rys.) oraz st } \\
\text { (numer WPS) }\end{array}$ & osując się & $\begin{array}{l}\text { Poz. nr } 10 \\
\text { (nr rys.) } \\
\text { Poz. nr. 15 } \\
\text { (nr rys.) }\end{array}$ & \\
\hline 015 & & & & & & \\
\hline 020 & & & & & & \\
\hline
\end{tabular}

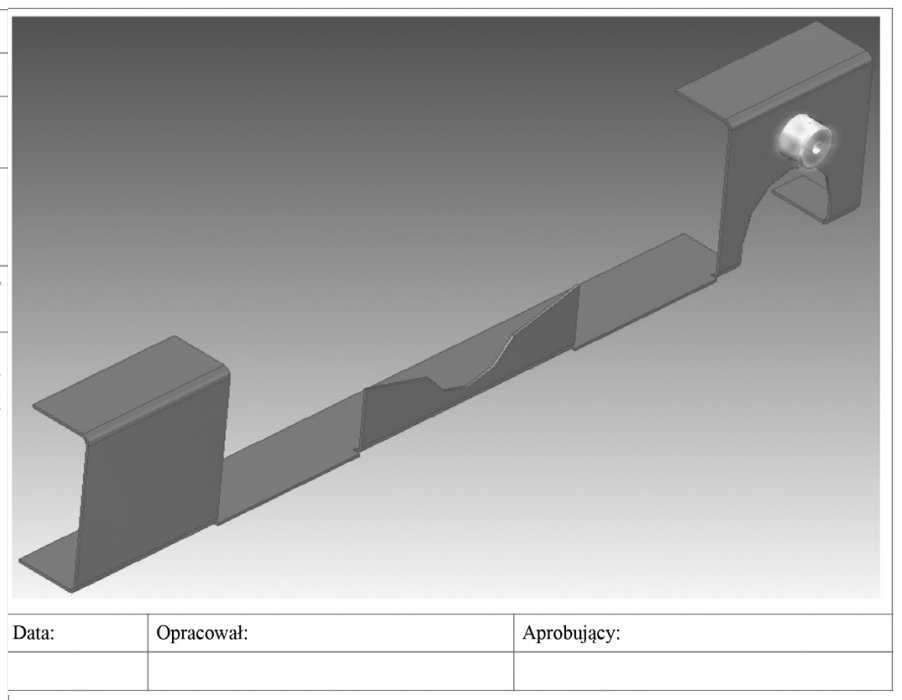

Rys. 5. Karta Technologiczna Nr 3/ABC - Etap - 3

Fig. 5. Operation sheet no. 3 / ABC - Stage - 3 


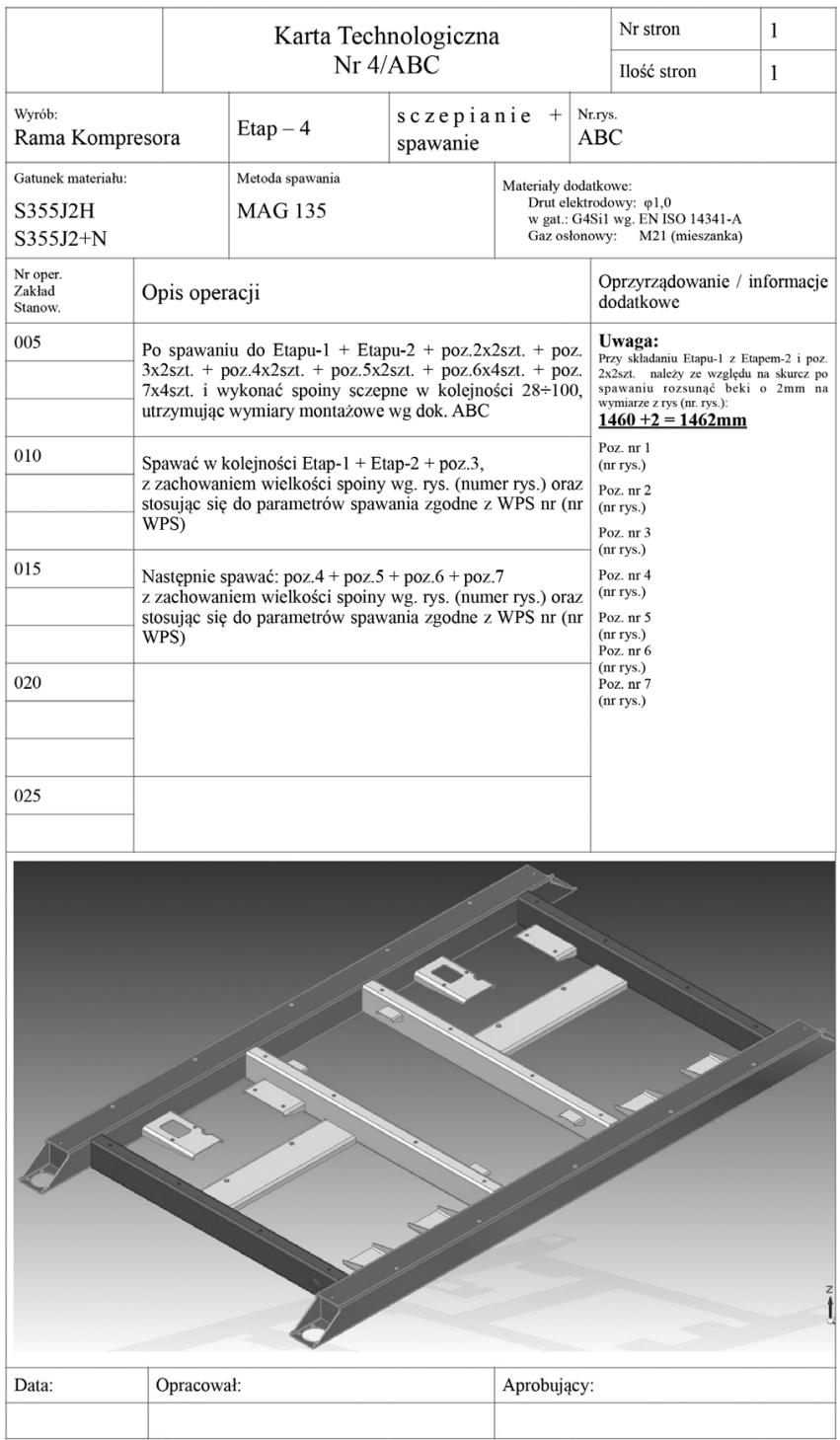

Rys. 6. Karta Technologiczna Nr 4/ABC - Etap - 4

Fig. 6. Operation sheet no. 4 / ABC - Stage -4

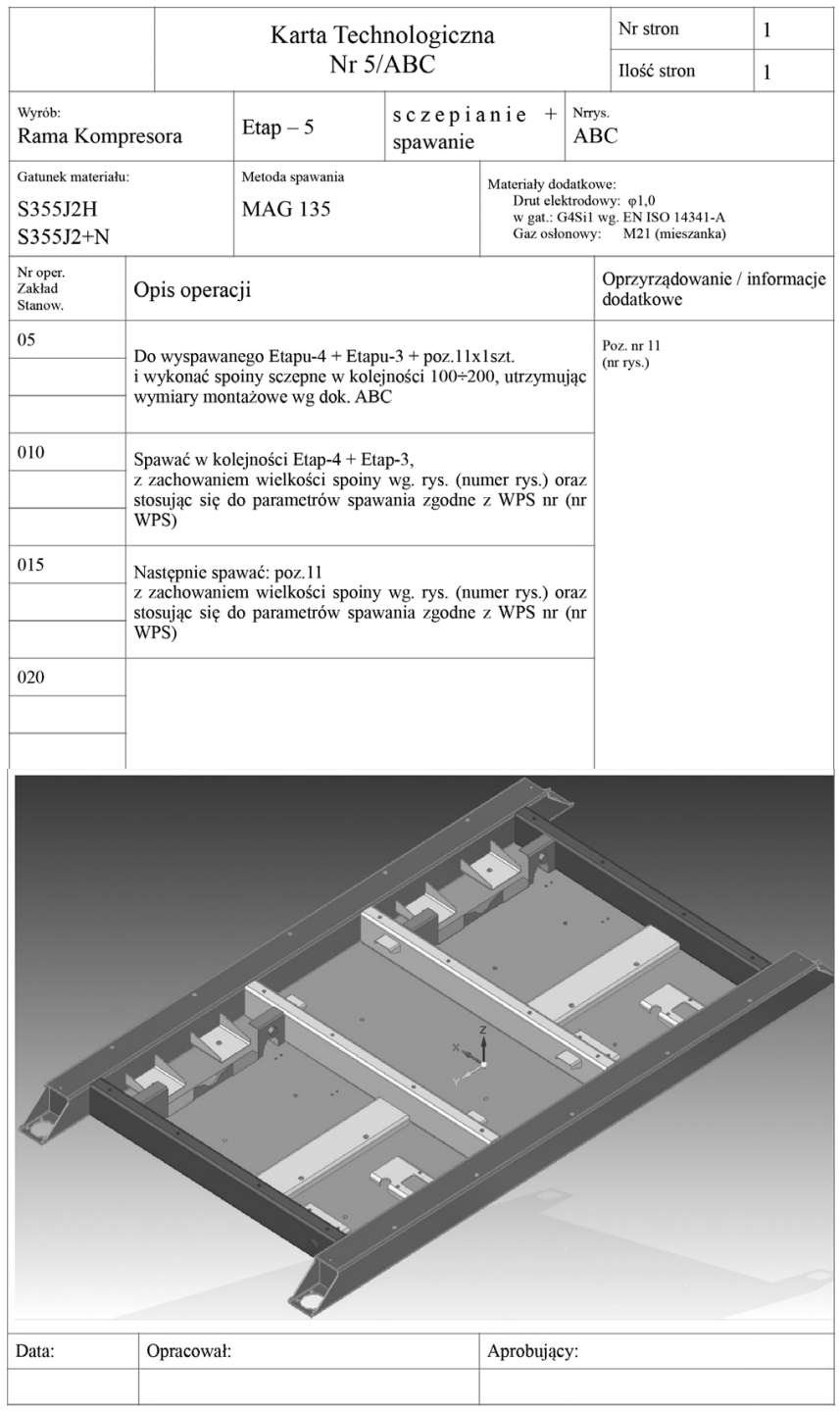

Rys. 7. Karta Technologiczna Nr 5/ABC - Etap - 5

Fig. 7. Operation sheet no. 5 / ABC - Stage -5

\section{Podsumowanie}

Przedstawiony plan spawania jest przykładem planu stosowanego przy spawaniu pojazdów szynowych. Plan ten bazuje na Kartach Technologicznych sczepiania i spawania. Obejmuje również wymagania dotyczące materiałów podstawowych oraz dodatkowych. Zwraca też uwagę na przygotowanie elementów do spawania, sczepiania oraz przebieg procesu spawania. Należy pamiętać, że częścią wspólną niezbędną dla prawidłowego wykonania konstrukcji są wymieniane powyżej procedury spawania WPS. Należy też pamiętać, że zgodnie z wymaganiami PN EN 15085, zanim wystawimy zakładowe procedury WPS dla danej konstrukcji musimy przeprowadzić proces kwalifikowania technologii spawania uzyskując tzw. WPQR.

\section{Literatura}

[1] Słania J.: Skóra J.: Plan spawania wymiennika ciepła chłodzonego powietrzem Przegląd spawalnictwa nr 2/2011,str. 19-26.

[2] Słania J.: Plany spawania. Teoria i praktyka. Agenda Wydawnicza SIMP, Warszawa 2013.

[3] Słania J.: Plan technologiczny spawania płyty gąsienicowej. Przegląd Spawalnictwa 2010, nr 3, str. $16-25$

[4] Słania J., Kaczor T.: Plan spawania zbiornika ciśnieniowego. Przegląd Spawalnictwa 2010, nr 4, str. 9 - 18.

[5] Słania J., Kwiecień L., Jarosiński J.: Plan spawania kotłów płomienicowo - płomieniówkowych. Przegląd Spawalnictwa 2010, nr 6, str 32 - 40.

[6] Słania J., Skóra J.: Plan spawania wymiennika ciepła chłodzonego powietrzem. Przegląd Spawalnictwa 2011, nr 2, str 16-22.

[7] Słania J.: Plan spawania carg płaszcza pieca obrotowego. Przegląd Spawalnictwa 2011, nr 2, str. 36-41.

[8] Słania J., Wodecki D.: Plan spawania belki poprzecznej dźwigu.Przegląd Spawalnictwa 2011, nr 2, str. 30-35

[9] Słania J.: Istota planów spawania. Przegląd Spawalnictwa 2011, nr 2, str 3-9.

[10] Słania J.: Plan spawania napraw bieżących kotłów parowych, wodnych i stałych zbiorników ciśnieniowych. Przegląd Spawalnictwa 2011, nr 2, str 22-30.
[11] Słania J., Kwiecień L., Jarosiński J.: Kotły płomienicowo - płomieniówkowe - plan spawania oraz kontroli i badań. Dozór Techniczny 2011, nr 2, str. $35-41$.

[12] Słania J., Chomiuk S., Dadak R.: Plan spawania dla konstrukcji uzupełniającej - trawresy. Przegląd Spawalnictwa 2012, nr 2, str 3 - 6.

[13] Słania J., Marcinkiewicz H., Kiełbik M.: Plan spawania elementu obudowy kopalnianej - osłony odzawałowej. Przegląd Spawalnictwa 2012, nr 2, str. 6 - 16.

[14] Słania J., Fryc H.: Spawanie pojazdów szynowych - plany spawania. Przegląd Spawalnictwa 2012, nr 2, str. 16 - 20

[15] Słania J.: Plan spawania stalowej kładki dla pieszych I. Przegląd Spawalnictwa 2012, nr 2, str. 20 - 24.

[16] Słania J.: Plan spawania stalowej kładki dla pieszych II. Przegląd Spawalnictwa 2012, nr 2, str. 24 - 26.

[17] Słania J., Urbańczyk P.: Technologia wytwarzania oraz plan kontroli jakości przegrzewacza pary kotła parowego wg PN-EN 12952-5. Przegląd Spawalnictwa 2012, nr 5, str. 29 - 41.

[18] Chromik D., Słania J.: Plan spawania ciśnieniowego zespołu rurowego Przegląd Spawalnictwa 2012, nr 11, str. 29 - 32. 